\title{
COMPORTAMENTO DAS AÇÕES DAS EMPRESAS LISTADAS NA B3 A PARTIR DA PUBLICAÇÃO DO RANKING MERCO BRASIL
}

\section{BEHAVIOR OF THE ACTIONS OF COMPANIES LISTED ON B3 FROM THE PUBLICATION OF RANKING MERCO BRASIL}

\author{
BRUNO EDUARDO SLONGO GARCIA \\ Professor e pesquisador na Uniandrade e tutor na Universidade Federal do Paraná (UFPR) \\ Doutorando em Administração - Universidade Federal do Paraná (UFPR) \\ Orcid: https://orcid.org/0000-0002-9271-6473 / E-mail: brunog.12@ufpr.br \\ Rua Ayrton Turra, 153, Bairro Cajuru, Curitiba/PR, CEP: 82.970-015 \\ CLAUDIO MARCELO EDWARDS BARROS \\ Professor da Universidade Federal do Paraná (UFPR) \\ Doutor em Contabilidade - Universidade Federal do Paraná (UFPR) \\ Orcid: https://orcid.org/0000-0001-7431-1627 / E-mail: claudiomedwards@hotmail.com \\ MARCOS WAGNER DA FONSECA \\ Professor Permanente do PPG em Contabilidade - Universidade Federal do Paraná (UFPR) \\ Doutor em Desenvolvimento Econômico - Universidade Federal do Paraná (UFPR) \\ Orcid: https://orcid.org/0000-0002-9804-6271 / E-mail: marcos.w.fonseca@gmail.com
}

Submissão: 23/08/2020. Revisão: 27/10/2020. Aceite: 03/01/2021. Publicação: 01/03/2021.

DOI: http://dx.doi.org/10.22277/rgo.v14i2.5776

\section{RESUMO}

Este estudo tem como objetivo verificar o comportamento das ações das empresas brasileiras listadas na B3, a partir da publicação do ranking de reputação corporativa Merco. Para isso, foi realizada uma pesquisa quantitativa e de caráter descritivo. Como fonte de dados foram utilizados os retornos das ações de 23 empresas brasileiras listadas no Ranking Merco, analisados por meio do estudo de eventos. Os achados levaram a identificação de retornos anormais nulos em 30\% das observações, enquanto em 70\% (16 ativos) da amostra os retornos se demonstraram anormais na janela da divulgação do Ranking Merco. Para explicar a diferença entre os retornos, menciona-se que quando a informação não é uma novidade ou foi integrada à cultura da companhia, a capacidade de sinalizar e promover retornos anormais é reduzida, desta forma, observa-se retornos anormais nulos e pulverizados. Para explicar o comportamento dos ativos é possível mencionar a relevância da informação e os processos cognitivos de identificação. O fato de algumas empresas estarem listadas em edições anteriores minimizou a relevância da informação e a identificação no mercado de ações, assim, a sinalização não obteve retornos anormais significativos a partir da colocação no Merco. Para tanto, este estudo contribui para compreender que a colocação em um ranking de reputação corporativa pode se apresentar como uma informação não relevante para o mercado, não promovendo processos de identificação com seus agentes. Para ocorrer a sinalização, esses processos devem ser observados.

Palavras-chave: Teoria da Sinalização. Retornos anormais. Reputação corporativa. 
Comportamento das ações das empresas listadas na B3 a partir da publicação do Ranking Merco Brasil

\begin{abstract}
This study aims to verify the behavior of the shares of Brazilian companies listed on B3, based on the publication of the Merco corporate reputation ranking. For this, a quantitative and descriptive research was carried out. As data source, the stock returns of 23 Brazilian companies listed in the Merco ranking were used, analyzed through the study of events. The findings led to the identification of null abnormal returns in $30 \%$ of the observations, while in $70 \%$ (16 assets) of the sample the returns were shown to be abnormal in the window for disclosing the Merco ranking. To explain the difference between the returns, it is mentioned that when the information is not new or the company culture has been integrated, the ability to signal and promote abnormal returns is reduced, thus, null and fragmented abnormal returns are observed. To explain the behavior of the assets, it is possible to mention the relevance of the information and the cognitive identification processes. The fact that some companies were listed in previous editions minimized the relevance of the information and the identification in the stock market, thus, the signaling did not obtain significant abnormal returns from the placement in Merco. To this end, this study contributes to understanding that the placement in a corporate reputation ranking can present itself as information that is not relevant to the market, not promoting identification processes with its agents. For signaling to occur, these processes must be observed.
\end{abstract}

Keywords: Signaling Theor. Abnormal returns. Corporate reputation.

\title{
1 INTRODUÇÃO
}

A reputação corporativa tem recebido atenção nos estudos sobre gestão (MONEY et al., 2017). As discussões a respeito do tema são centradas na estratégia corporativa, sinais positivos e negativos, cultura e a compreensão das partes relacionadas. Essas questões podem ser melhor compreendidas na relação entre organização e público interessado (SCHOEMAKER, 1990; HATCH; SCHULTZ, 1997).

Schoemaker (1990), por exemplo, discute em seu artigo sobre estratégia, a existência de uma relação entre reputação e cultura que permite as organizações obterem ganhos monetários. Para o autor (SCHOEMAKER, 1990), o intermediador é o comportamento, devido a isso, a reputação é complexa e ainda pouco explorada nos estudos sobre o tema. Barney (1991) amplia a compreensão de ganhos de Schoemaker (1991) para a vantagem competitiva sustentável, assim, a reputação positiva entre clientes e fornecedores é um recurso que permite que as organizações mantenham suas atividades e, consequentemente, seus ganhos. Um ponto de convergência entre os estudos mencionados é mantido por meio da história, desta forma, os eventos históricos são responsáveis por determinar a reputação, tornando imperfeitamente imitável.

Hatch e Schultz (1997) avançam e exploram questões cognitivas da reputação corporativa. Cultura, imagem e identidade são processos circulares e interligados, assim sendo, promovem a construção de uma reputação corporativa baseada em trocas de símbolos e significados entre organização e público. Observa-se que a responsabilidade de administrar a reputação compete a organização, contudo, seu significado ocorre no processo cognitivo circular entre organização e público. A partir de Hatch e Schultz (1997), autores como Dowling (2016) e Walsh et al. (2016) avançam para compreender como as organizações incorporam a reputação corporativa as suas estratégias e os processos psicológicos e cognitivos que permitem aos indivíduos identificá-las. 
Devido a diversidade de abordagens teóricas mencionadas nessa introdução, a reputação corporativa, inicialmente, foi compreendida como a capacidade das organizações em administrar sua imagem e projetá-la para o mercado. É um recurso intangível e duradouro, capaz de gerar benefícios as organizações (THOMAZ; BRITO, 2010). Para superar esse conceito e avançar as abordagens seminais propostas por Schoemaker (1990), Barney (1991), Hatch e Schultz (1997) e Dowling (2016) conceituam reputação como admiração e respeito que os indivíduos possuem sobre uma organização em um determinado momento.

Nesse contexto, a reputação corporativa é abordada como um recurso intangível que caracteriza a organização e integra os sistemas cognitivos dos agentes, como os clientes. Esta abordagem teórica tem implicações sobre como os agentes identificam a empresa frente aos seus concorrentes. Os comportamentos dos agentes são influenciados pela admiração e respeito que os indivíduos desenvolvem a partir das ações da empresa (HATCH; SCHULTZ, 1997; GÓIS; DE LUCCA; SOUZA, 2017; DOWLING, 2016).

Baseado nisso, a identificação cognitiva pode ser acionada por diversos mecanismos, como a divulgação de um ranking, como o Monitor Empresarial de Reputação Corporativa (Merco). O Merco publica um ranking periódico com as cem empresas brasileiras com melhor reputação corporativa. Esse ranking é uma ferramenta multistakeholder que permite avaliações sobre a identificação do público alvo em cinco níveis, os quais são coordenados por comitês de direção, analistas financeiros, Organizações Não Governamentais (ONG'S), sindicatos, associações de consumidores, jornalistas de informações econômicas, professores da área de negócios, gerentes de mídias sociais influentes, Merco consumo, Merco pessoas e avaliação de méritos. A composição do ranking busca demonstrar como as empresas listadas trabalham a reputação e como seu mercado a identifica.

Essa relação entre ações de reputação das organizações (colocação em um ranking), processos cognitivos de identificação e resultados, permanecem pouco explorados na literatura. Money (2017) demonstra essa lacuna em seu estudo. Para o autor as abordagens orientadas para ações estratégicas (colocação em um ranking), observação do público interessado e resultados esperados são estudos futuros que podem contribuir para a compreensão da reputação corporativa.

Os autores deste estudo abordam a composição de rankings como o Merco, como resultado das ações das organizações, as quais serão identificadas pelo seu público. Neste sentido, os resultados podem ser evidenciados nos ativos das companhias, indicando a possibilidade de um comportamento de prenúncio para os agentes do mercado (DALMÁCIO, 2009). Esse comportamento é abordado e explicado na Teoria da Sinalização. O pressuposto é a ação de sinalizar por meio da emissão de informações que visam suprimir os efeitos das assimetrias de mercado para o investidor. Rankings corporativos, especificamente, podem caracterizar avisos ao mercado e ocasionar mudanças no cognitivo e nos comportamentos dos investidores e, consequentemente, resultar em oscilações nas ações das companhias, denominados de retornos anormais.

Diante do exposto, o presente estudo busca responder a seguinte questão de pesquisa: "qual o comportamento das ações das empresas brasileiras listadas na B3 a partir da publicação do ranking de reputação corporativa Merco?" Consequentemente, o objetivo da pesquisa consiste em verificar o comportamento das ações das empresas brasileiras listadas na B3 a partir da publicação do ranking de reputação corporativa Merco.

Em seus estudos, autores como Cardoso, Luca, Lima e Vasconselos (2013) contribuem e indicam insights que corroboram com a discussão desta pesquisa, ao analisarem o desempenho financeiro e a reputação de companhias. Em seus achados, são evidenciadas 
relações de interdependência e de valor agregado, haja visto que os processos cognitivos de identificação permanecem sendo explorados de forma circular. Argumento semelhante é encontrado no estudo proposto por De Luca et al. (2015), ao demonstrarem o desempenho da organização e a reputação corporativa como influenciadores mútuos. Reitera-se, que essa relação compõe a vantagem competitiva.

Considerando os achados das pesquisas mencionadas e o objetivo deste estudo em avançar na discussão sobre a compreensão de questões cognitivas, a contribuição é justificada ao instigar discussões sobre a influência da reputação corporativa das empresas e do mercado de capitais. Além disso, contribui para a temática da reputação corporativa sob a ótica do movimento circular entre indivíduos, identificação e ações estratégicas das organizações.

Ademais, a vista da contribuição para a prática, esta investigação busca por evidências que podem sustentar o fortalecimento do monitoramento das informações para os sinais que se encontram intrínsecos nas estratégias das organizações (como a colocação em um ranking), o que permitem aos investidores identificarem possíveis retornos acionários. Por fim, contribui para a compreensão do como as informações podem perder a característica de sinalizadora, isto é, quando os processos cognitivos não são estabelecidos, a sinalização não possui efeitos.

Em relação a estrutura, esta pesquisa está dividida em quatro seções (após esta introdução): (I) o referencial teórico do estudo; (II) o percurso metodológico; e por fim, (III) as análises, discussões e conclusões.

\section{REPUTAÇÃO CORPORATIVA}

As ideias seminais sobre reputação corporativa (ASHFORTH; MAEL, 1989), a abordam como resultado de aspectos cognitivos. Desta forma, permitem que ocorra o reconhecimento e a identificação por grupos de indivíduos com comportamentos distintos, mas, com ideologias semelhantes. Ainda sob o enfoque das ideias seminais, a ideologia é uma dimensão a qual a reputação corporativa se conecta, permitindo a produção de significados da vida social com as ideias definidas pelos seus integrantes (EAGLETON, 1997).

Nesta lógica, compreende-se que as pessoas a seguem e intencionalmente a defendem por equivalência com seus objetivos de vida. Aproximando o interposto com a realidade empresarial, a identificação com os valores organizacionais inicia no significado que é produzido nas relações e interpretações de determinado grupo.

A partir desse argumento, as pesquisas sobre reputação corporativa iniciam na perspectiva de valor agregado. Isto é, se todos os interessados nas atividades da firma são observadores ativos, então, irão estabelecer a sua visão fortalecida no valor de todas as atividades desempenhadas pela firma para alcançar o mercado (FONBRUM; VAN RIEL, 1997; DUTRA; PARENTE, 2018; RAVASI et al., 2018). O reconhecimento e identificação dos valores nas organizações está concentrado na geração de valor por parte da firma. Essa perspectiva coloca as ações que a empresa executa como responsável pelo processo de identificação (DOWLING, 2001), demonstrando a geração de valor para o mercado (GINESTI, CALDARELLI; ZAMPELLA, 2018).

Neste caminho que relaciona reputação corporativa como a cognição, a Teoria da Identidade Social possibilita discussões sobre quais os aspectos cognitivos que levam a identificação com as ações e valores das organizações. Por exemplo, as empresas têm a responsabilidade em conhecer as causas apreciadas por seus stakeholders, como o envolvimento com causas sociais. (THOMAZ; BRITO, 2010; DOWLING, 2016). 
Em suma, a reputação corporativa é uma variável relevante para a formação da identidade social das organizações. Pressões ambientais exercidas sobre as organizações na década de 1980, por exemplo, levaram a evolução das estratégias de adequação. Mudanças conceituais e socialmente aceitáveis pressionaram a adequação das práticas empresariais e seus impactos no meio ambiente (ROBINSON, 2000).

É compreensível que a identificação com as organizações indicará o posicionamento das ações empresariais interpretadas por seu público. Neste sentido, a identificação da organização com o seu mercado deverá ser positiva (ARGENTI; FORMAN, 2002; DUTRA; PARENTE, 2018). A reputação é o produto final da relação ideológica de troca entre agente e empresa, e dependendo de como é gerida, pode ser sinalizada ao mercado. Por fim, apresentadas as definições a respeito da reputação, faz-se necessário compreender como esse fenômeno organizacional e social age nos retornos acionários.

\subsection{RETORNO ACIONÁRIO E A TEORIA DA SINALIZAÇÃO}

Diante da contextualização acerca da reputação corporativa e na busca por compreender se é possível ocasionar retornos diferenciados nos mercados de capitais, é necessário abordar o conceito de retornos acionários. Conceitualmente, os retornos da performance financeira do investimento são obtidos com a diferença entre o valor do investimento e as remunerações recebidas (PITTA, 2000).

Nos mercados perfeitos, as informações não modificam o comportamento dos retornos das ações. O contrário é observado nos mercados imperfeitos, em que as informações proporcionam conhecimentos diferenciados, o que neste caso, se tem a assimetria da informação e, por consequência, os retornos anormais (JENSEN; MECKLING, 1976; CAMARGOS; BARBOSA, 2013; FRANCO; BACH; SILVA, 2016). Neste contexto, a Teoria da Sinalização fornece uma lente teórica para estudar e compreender os retornos anormais a partir das assimetrias de mercado.

A Teoria da Sinalização pode ser compreendida por meio do exemplo de um empreendedor que possui a oportunidade de investir e detém o conhecimento a respeito do risco desse projeto. Em contrapartida, o mercado não possui as mesmas informações e avalia o investimento pela média de mercado. Assim, a assimetria de informação torna projetos de alto risco beneficiários da informação, prejudicando projetos de baixo risco que arcam com custos de capital maiores que o devido. A figura do empreendedor poderá transmitir um sinal ao mercado com o valor fidedigno da média do retorno do projeto (CARNAÚBA, 1993; LELAND; PYLE, 1977).

Diante do exposto, a sinalização tratará dos problemas de assimetria informacional, emitindo sinais ao mercado (DALMÁCIO, 2009). Alguns estudos buscam discutir a relação entre reputação corporativa e Teoria da Sinalização, por exemplo, De Lucca et al. (2014). Os autores demonstram, por meio da Teoria da Sinalização, que a criação de riqueza das empresas escolhidas é resultado da reputação corporativa reforçada por sinais positivos.

O estudo de Lopes et al. (2017) utiliza um ranking de reputação corporativa para analisar a relação com o disclosure socioambiental e a criação de valor para as empresas. Os achados dos estudos demonstram que o disclosure socioambiental é positivamente relacionado a reputação corporativa, atuando como sinalização para a reputação corporativa. Contudo, o disclosure não demonstra criar valor para a organização, diferente do observado na reputação corporativa.

Estudos internacionais, como os apresentados por Ageeva et al. (2018) examinam, na perspectiva do marketing, como os sites corporativos podem exercer a sinalização. Para os 
autores, os reforços positivos resultam em favorabilidade e, por consequência, na reputação corporativa. Walsh, Schaarschmidt e Ivens (2017) estudam no varejo a relação entre reputação corporativa baseada no cliente. Os autores compreendem que existem sinalizações que originam resultados relacionais entre a reputação atribuída aos varejistas por parte dos clientes.

O presente estudo busca avançar às pesquisas mencionadas nessa seção, compreendendo que os aspectos de identificação, denominados por Walsh, Schaarschmidt e Ivens (2017) como relacionais, são determinantes para que ocorra a sinalização a partir de um ranking que elucida a reputação corporativa e, posteriormente, mudanças nos retornos dos ativos em bolsa de valores como a B3. Ageeva et al. (2018) identificam que sinais positivos podem ter resultados favoráveis, contudo, não avançam a compreensão para quando esses sinais deixam de promover resultados para as companhias. O mesmo caminho é percorrido por Lopes et al. (2017), ao afirmarem que as justificativas não abordam questões cognitivas do mercado e permanecem na perspectiva de criação de valor por parte da companhia. Por fim, apresentados os entendimentos conceituais, a próxima seção descreve os procedimentos metodológicos e na sequência a apresentação dos resultados.

\section{PROCEDIMENTOS METODOLÓGICOS}

Dado o objetivo do presente estudo em verificar o comportamento das ações das empresas brasileiras listadas na B3 a partir da publicação do ranking de reputação corporativa Merco, foi realizada uma pesquisa quantitativa e de caráter descritivo. Como fonte de dados foram utilizados os retornos diários das ações e analisados por meio do estudo de eventos. $\mathrm{O}$ estudo de eventos é uma metodologia que possibilita analisar os impactos de determinados eventos sob o comportamento de um ou vários ativos. A essência dessa técnica de análise está na mensuração do impacto ocasionado nos títulos por meio da entrada de uma informação no mercado que sinaliza ao investidor as possibilidades de ganhos no investimento (AGUIAR, CORRAR; BATISTELA, 2004).

Trata-se de um método robusto que utiliza dados secundários para estudar o impacto dos ativos sobre a valoração das ações das empresas. Neste sentido, o estudo de eventos atua como um avaliador de comportamentos variantes a partir de eventos específicos que alteram o resultado, até então esperado, para retornos anormais (BARROS; LOPES; ALMEIDA, 2019). Já o retorno normal é o produto esperado caso o evento não ocorra. Na presença do evento, a variância pode conter informações relevantes a serem analisadas (NOVIS NETO; SAITO, 2003; SILVA, NORILLER, D. M. SILVA; SOUZA, 2018).

Para instrumentalizar esta pesquisa, utilizou-se dos conceitos de Mackinlay (1997) e Campbell, Lo e Mackinlay (1997), ao estabelecerem sete passos para operacionar um estudo de eventos, sendo: (1) definição do evento; (2) critérios e seleção da amostra; (3) medição dos retornos normais e anormais; (4) procedimentos para estimação; (5) procedimentos para teste; (6) resultados empíricos; e (7) interpretações pertinentes e considerações finais, discutidos nas próximas seções.

\subsection{DEFINIÇÃO DO EVENTO}

Para o estudo proposto, analisou-se como o evento a divulgação pública da composição do Ranking de reputação corporativa do ano de 2017 no Monitor Empresarial de Reputação Corporativa (Merco). Este ranking foi selecionado pois antecedeu as eleições presidenciais de 2018, o que minimizou os eventos secundários. Considerando o estudo 
proposto por Camargos e Barbosa (2003), a data anterior ao evento corresponde ao comportamento do mercado e os dias posteriores identificam a reação do mercado ao evento de divulgação do Ranking Merco.

A data de divulgação do Merco corresponde a data zero, a data anterior é denominada janela de estimação e a data posterior será a janela pós-evento. Próximo a data zero foram estipulados -5 dias e +5 dias, estes correspondem ao período antes e após a divulgação do ranking.

Em relação a janela do evento, o número de observações deverá adequar-se à possibilidade de identificar eventuais comportamentos considerados relevantes para as ações, contudo, a decisão passa a ser subjetiva e a critério do pesquisador (MATSUMOTO; BARALDI; JUCÁ, 2018).

A Figura 1 demonstra a datas observadas.

Figura 1 - Janela do Evento
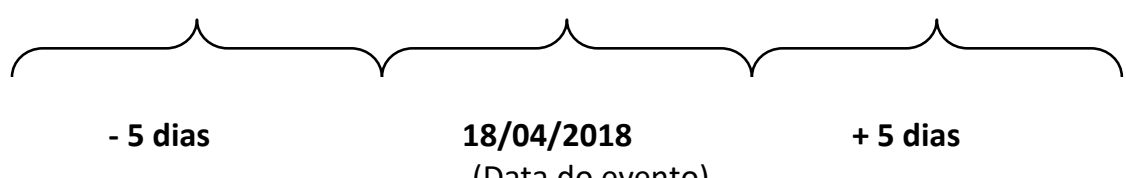

Fonte: adaptado de Campbell, Lo e Mackinlay (1997).

A escolha do número de dias foi realizada considerando a sensibilidade do mercado acionário e procurando suprimir possíveis oscilações que não fossem oriundas ao evento da divulgação do Ranking de Reputação Corporativa - Merco ou eventos secundários. A data zero foi considerada na divulgação do ranking de Reputação Corporativa Merco em 18/04/2018 de forma pública no site da Revista Exame, as demais datas utilizadas serão apresentadas nos tópicos seguinte.

\subsection{CRITÉRIOS E SELEÇÃO DA AMOSTRA}

A população deste estudo é composta por 100 empresas listadas no Ranking Merco. A amostra compreende as companhias brasileiras listadas no ranking e com negociação de ações na Bolsa Balcão Brasil (B3), totalizando 37 ativos. As companhias foram divididas nos respectivos setores do Merco (Quadro 1).

Os retornos das ações foram obtidos pelo preço de cotação dirária disponível no banco de dados do Yahoo Finance. Foi considerado no valor das ações o pagamento de dividendos, assim como no estudo de Carmargos e Barbosa (2003) e Schmidt, Martins, Santos e Kloeckner (2018), a fim de evitar que eventos secundários provoquem distorções aos resultados do estudo. 
Comportamento das ações das empresas listadas na B3 a partir da publicação do Ranking Merco Brasil

Quadro 1 - Relação das Empresas Brasileiras Listadas no Ranking Merco

\begin{tabular}{|c|c|c|c|}
\hline $\begin{array}{c}\text { Empresas Brasileiras } \\
\text { Listadas no Merco }\end{array}$ & Ativos & $\begin{array}{c}\text { Empresas Brasileiras } \\
\text { Listadas no Merco }\end{array}$ & Ativos \\
\hline \multicolumn{2}{|c|}{ Alimentos, Bebidas e Fumo } & \multicolumn{2}{|c|}{ Mineração, Siderurgia e Metalurgia } \\
\hline $\begin{array}{l}\text { Ambev } \\
\text { BRF } \\
\text { JBS }\end{array}$ & $\begin{array}{l}\text { ABEV3 } \\
\text { BRFS3 } \\
\text { JBSS3 }\end{array}$ & $\begin{array}{l}\text { Gerdau } \\
\text { Vale } \\
\text { Usiminas }\end{array}$ & $\begin{array}{c}\text { GGBR3, GGBR4, GOAU3, GOAU4 } \\
\text { VALE3 } \\
\text { USIM5 }\end{array}$ \\
\hline \multicolumn{2}{|c|}{ Bens de Capital } & \multicolumn{2}{|c|}{ Química e Petroquímica } \\
\hline WEG & WEGE3 & Braskem & BRKM3, BRKM5 \\
\hline \multicolumn{2}{|c|}{ Cosméticos e Perfumaria } & \multicolumn{2}{|c|}{ Roupas e Calçados } \\
\hline $\begin{array}{l}\text { Avon } \\
\text { Natura }\end{array}$ & $\begin{array}{l}\text { AVON34 } \\
\text { NATU3 }\end{array}$ & $\begin{array}{c}\text { Alpargatas } \\
\text { Hering }\end{array}$ & $\begin{array}{c}\text { ALPA3, ALPA4 } \\
\text { HGTX3 }\end{array}$ \\
\hline \multicolumn{2}{|c|}{ Eletroeletrônicos } & \multicolumn{2}{|r|}{ Seguros } \\
\hline \multirow[b]{2}{*}{ Whirpool } & \multirow[b]{2}{*}{ WHRL4 } & Porto Seguro & PSSA3 \\
\hline & & \multicolumn{2}{|c|}{ Serviços de Saúde } \\
\hline \multicolumn{2}{|c|}{ Energia } & Fleury & FLRY3 \\
\hline Petrobras & PETR4 & \multicolumn{2}{|l|}{ Serviços Diversos } \\
\hline CPFL & CPFE3 & Localiza & RENT3 \\
\hline Eletrobrás & ELET6 & \multicolumn{2}{|c|}{ Serviços Financeiros } \\
\hline \multicolumn{2}{|c|}{ Indústria da Construção } & \multirow{4}{*}{$\begin{array}{l}\text { Itaú Unibanco } \\
\text { Bradesco } \\
\text { Banco do Brasil }\end{array}$} & \multirow{4}{*}{$\begin{array}{l}\text { ITUB4, ITSA4 } \\
\text { BBDC3, BBDC4 } \\
\text { BBAS3 }\end{array}$} \\
\hline Gafisa & GFSA3 & & \\
\hline \multicolumn{2}{|c|}{ Industria Digital } & & \\
\hline TOTVS & TOTS3 & & \\
\hline \multicolumn{2}{|c|}{ Varejo } & \multicolumn{2}{|c|}{ Telecomunicações } \\
\hline \multirow{3}{*}{$\begin{array}{l}\text { Renner } \\
\text { Magazine Luiza } \\
\text { Raia Drogasil }\end{array}$} & \multirow{3}{*}{$\begin{array}{l}\text { LREN3 } \\
\text { MGLU3 } \\
\text { RADL3 }\end{array}$} & Telefônica Vivo & VIVIT4 \\
\hline & & \multicolumn{2}{|c|}{ Transporte e Logística } \\
\hline & & \multirow{3}{*}{$\begin{array}{c}\text { GOL } \\
\text { Embraer }\end{array}$} & \multirow{3}{*}{$\begin{array}{c}\text { GOLL4 } \\
\text { EMBR3 }\end{array}$} \\
\hline Madeir & lose & & \\
\hline Fibria & FIBR3 & & \\
\hline
\end{tabular}

Fonte: Ranking Merco (2017).

\subsection{MEDIÇÃO DOS RETORNOS NORMAIS E ANORMAIS}

A mensuração do impacto foi realizada com base no modelo proposto por Campbell, Lo e Mackinlay (1997); Mackinlay (1997) e Matsumoto, Baraldi e Jucá (2018) os retornos anormais e normais são caracterizados conforme equação 1 :

$A R_{\text {it }}=\mathrm{R}_{\text {it }}-\mathrm{E}\left(\mathrm{R}_{\mathrm{it}} / \mathrm{X}_{\mathrm{t}}\right)$

$A R_{\text {it: }}$ Representa o retorno anormal da ação $i$ na data $t$.

$\mathrm{R}_{\mathrm{it}}$ : É o retorno real da ação $i$ na data $t$.

$E\left(R_{i t}\right)$ : Representa o retorno normal da ação $i$ na data $t$.

$X_{t}$ : Refere-se à informação para o retorno normal da ação como uma condicionante.

Há três maneiras possíveis para medir os retornos anormais das ações. Para este estudo optou-se pelo modelo de mercado que relaciona os retornos da ação ao do portfólio de mercado (CAMPBELL; LO; MACKINLAY, 1997). Este modelo amplifica a percepção dos efeitos de eventos isolados e reduz a variância dos retornos anormais (AGUIAR, CORRAR; BATISTELLA, 2004). O modelo estatístico é representado pela regressão linear simples (equação 2):

$R_{i t}=\alpha i+\beta i R m t+E i t$

$\mathrm{R}_{\mathrm{it}}$ : Retorno da ação $i$ na data $t$.

ai + ßi: Coeficiente do intercepto e de declividade para a ação $i$.

Rmt : Retorno do portifólio de mercado na data $t$. 
Eit: Erro para a ação $i$ na data $t$.

De acordo com o modelo econométrico proposto, foi possível testar a hipótese de pesquisa das possíveis manifestações dos retornos anormais, a partir das informações da divulgação do ranking de reputação corporativa proposto pelo Merco, que atua como sinalização para o mercado.

\subsection{PROCEDIMENTOS PARA ESTIMAÇÃO}

Para a estimação do valor de $\alpha$ (alfa) e $\beta$ (beta) foi utilizado o método dos mínimos quadrados (MMQ). Para tanto, foi calculado o logaritmo neperiano (Ln) para estimação precisa dos retornos, conforme equação 3.

$r=\ln (\mathrm{P} t / \mathrm{P}(t-1))$

Onde:

$r$ : é a taxa de retorno

Pt: é o preço da ação na data $t$

$P$ t-1: é o preço da ação na data $t-1$

A equação (3) corresponde ao retorno calculado em um período único, como em um regime de capitalização contínua. O retorno estimado será diário e o período utilizado será de -5 e +5 dias do evento de divulgação do ranking de Reputação Corporativa Merco, considerando que em períodos maiores outras oscilações advindas de outros eventos poderiam influenciar os resultados.

A Tabela 1 apresenta os valores estimados para $\alpha$ e $\beta$ calculados na janela de estimação, para compor o cálculo dos retornos normais e anormais.

Tabela 1 - Valores Estimados para Alfa e Beta

\begin{tabular}{ccccc}
\hline Ativo & Coeficiente $\boldsymbol{\beta}$ & $\begin{array}{c}\boldsymbol{\sigma}^{\mathbf{2}} \text { da } \\
\text { regressão }\end{array}$ & teste $\boldsymbol{t}$ do $\boldsymbol{\beta}$ & Coeficiente $\boldsymbol{\alpha}$ \\
\hline ABEV3 & 0,4674 & 0,0091 & 10,36 & 0,0008 \\
ALPA3 & 0,3940 & 0,0257 & $2,89^{*}$ & 0,0019 \\
ALPA4 & 0,7541 & 0,0178 & $5,044^{*}$ & 0,0009 \\
BBAS3 & 1,6799 & 0,0125 & $9,782^{*}$ & $-0,0005$ \\
BBDC3 & 1,2732 & 0,0099 & 25,93 & $-0,0002$ \\
BBDC4 & 1,2550 & 0,0084 & $18,71 *$ & 0,0000 \\
BRFS3 & 0,1437 & 0,0506 & $\mathbf{0 , 5 7 4 2}$ & $-0,0001$ \\
BRKM3 & 0,5795 & 0,0232 & $4,359^{*}$ & 0,0012 \\
BRKM5 & 0,5845 & 0,0180 & 6,574 & 0,0008 \\
CPFE3 & 0,2165 & 0,0149 & 2,950 & $-0,0003$ \\
FIBR3 & $-0,1040$ & 0,0236 & $\mathbf{0 , 4 3 4 1 *}$ & 0,0033 \\
FLRY3 & 0,5370 & 0,0176 & 6,163 & 0,0006 \\
GFSA3 & 0,9013 & 0,0316 & $6,033^{*}$ & $-0,0027$ \\
GGBR4 & 1,4431 & 0,0195 & 14,95 & $-0,0005$ \\
GOAU4 & 1,7188 & 0,0223 & $12,95 *$ & $-0,0005$ \\
GOLL4 & 1,6333 & 0,0295 & 11,20 & 0,0027 \\
HGTX3 & 0,9542 & 0,0202 & 9,55 & 0,0003 \\
ITUB4 & 1,1739 & 0,0079 & $19,82^{*}$ & 0,0001 \\
MGLU3 & 1,5389 & 0,0367 & 8,48 & 0,0045 \\
PSSA3 & 0,4093 & 0,0158 & 5,23 & 0,0017 \\
RADL3 & 0,5408 & 0,0136 & 8,03 & $-0,0001$ \\
RENT3 & 0,7723 & 0,0158 & 9,92 & 0,0026 \\
TOTS3 & 0,2932 & 0,0162 & 3,65 & 0,0003 \\
USIM5 & 1,8854 & 0,0237 & 16,09 & 0,0006 \\
VALE3 & 0,9700 & 0,0184 & $4,07^{*}$ & 0,0002 \\
VIVIT4 & 0,5581 & 0,0095 & 11,88 & 0,0000 \\
\hline
\end{tabular}


Comportamento das ações das empresas listadas na B3 a partir da publicação do Ranking Merco Brasil

\begin{tabular}{ccccc}
\hline WEGE3 & 0,7205 & 0,0138 & 10,57 & 0,0004 \\
WHRL4 & 0,0516 & 0,0266 & $\mathbf{0 , 3 9 3 1}$ & 0,0020 \\
AVON34 & 0,2367 & 0,0321 & 1,49 & $-0,0023$ \\
ELET6 & 1,5403 & 0,0310 & 10,06 & $-0,0015$ \\
EMBR3 & 0,4765 & 0,0219 & 4,40 & 0,0004 \\
GGBR3 & 1,1483 & 0,0222 & 10,49 & 0,0004 \\
GOAU3 & 1,2855 & 0,0199 & 13,09 & 0,0000 \\
ITSA4 & 1,1051 & 0,0081 & $26,06 *$ & 0,0005 \\
LREN3 & 1,0153 & 0,0131 & 15,70 & 0,0005 \\
NATU3 & 1,0110 & 0,0188 & 10,90 & $-0,0002$ \\
PETR4 & 1,5559 & 0,0140 & 22,55 & $-0,0002$ \\
\hline
\end{tabular}

Nota: * valores obtidos após erro padrão robusto.

Fonte: dados da pesquisa (2018).

De acordo com os resultados para estimação dos coeficientes $\alpha$ e $\beta$, a Tabela 1 apresenta o teste $t$ para estimação dos mesmos. Para analisá-los, são considerados os valores do teste $t$ que apresentam significância estatística (5\%) e indicam que o beta estimado para calcular os retornos anormais é adequado. Embora alguns valores do coeficiente estejam abaixo de $1 \%$, o teste $t$ permite a utilização como estimadores dos retornos. São destacados os ativos BRFS3 (0,5742), FIBR3 $(\mathbf{0 , 4 3 4 1 )}$ e WHRL4 $(\mathbf{0 , 3 9 3 1 )}$, que apresentaram valores não significativos do teste $t$, para que as estimações não sejam prejudicadas, os mesmos foram removidos da amostra.

\subsection{TESTE DE HIPÓTESES}

Para verificar o comportamento das ações das empresas listadas no Merco a partir da publicação do ranking de reputação corporativa, foi realizado o Teste de Hipótesespara interpretação dos retornos anormais. Estes testes representam o principal critério de constação de presença ou de ausência de reações importantes no preço das ações de companhias que compõem a listagem Merco. Defende-se a existência de retornos oscilantes (anormais) após a divulgação pública da composição do ranking. Como tangenciado na revisão de literatura, há espaço para compreensão de que a valoração dos ativos listados pode ocorrer de maneira difusa, ou seja, podem emergir retornos anormais positivos ou negativos na janela de eventos utilizada. Dada a plausibilidade dessa expectativa e adicionado ao fato de que a interpretação de retornos anormais se dá por meio da determinação de testes $t$ associados ao retornos calculados, tem-se que os Testes de Hipóteses empregados nesse estudo são bilaterais. Nesse sentido, a declaração dos testes é dada por:

Hipótese nula : Os retornos anormais são nulos.

Hipótese alternativa: Os retornos anormais são diferentes de zero.

Os Teste de Hipóteses direcionados a essa pesquisa são conduzidos por meio do confronto de valores críticos da distribuição $t$-student e o valor de $t$ calculado especificamente para os retornos anormais contidos na Janela de Eventos. Esse confronto foi realizado tendo como referência os valores críticos $t$ de 1,64, 1,96 e 2,57 para a significância estatística de $10 \%, 5 \%$ e $1 \%$, respectivamente (MACKINLAY, 1997; BENNINGA, 2009) . Isso significa que para saber se determinado retorno anormal é nulo ou significativo sob o ponto de vista estatístico, cada retorno calculado para a Janela de eventos foi dividido pelo erro-padrão proveniente da regressão computada para a calcular os parâmetros (alfa e beta) da janela de estimação. Caso a razão entre o retorno anormal calculado e o respectivo erro-padrão seja menor o valor crítico t, tem-se que o retorno estará na área de hipótese nula e, portanto, será considerado 
igual a zero. Caso contrário, o retorno será considerado significativamente positivo ou negativo, dado que o teste é bilateral.

\subsection{PROCEDIMENTOS PARA TESTE}

Após os parâmetros foram calculados os retornos anormais e enunciados os procedimentos para o teste. Para tanto, a estatística utilizada será o teste $t$, para estimar a significância dos diversos níveis dos retornos anormais. A fim de obter a padronização de cada retorno anormal, é apresentada a equação (4) e (5).

$Z A R_{i}=A R_{i} / \sigma i$

Onde:

$Z A R_{i}$ : retorno anormal padronizado (hipótese nula $=0$ )

$A R_{i}$ : retorno anormal da ação $i$

$\sigma i$ : desvio-padrão da ação i no período utilizado

O valor de $t$ é estimado pela equação (5):

$$
t=\frac{\sum A R i}{\sqrt{n}}
$$

A equação (5) determina a distribuição normal com média $\mu$ das variáveis randômicas independentes e padronizadas, considerando a soma dos valores esperados em que a variância será o número de variáveis integrantes da amostra n.

\subsection{TESTES DOS PRESSUPOSTOS}

Os ativos que integraram a amostra foram submetidos aos testes dos pressupostos para testes paramétricos, conforme protocolo de análise descrito na Quadro 2.

Quadro 2 - Protocolo de Procedimentos

\begin{tabular}{|c|l|l|c|}
\hline & \multicolumn{1}{|c|}{$\begin{array}{c}\text { Procedimentos } \\
\text { Estatísticos }\end{array}$} & \multicolumn{1}{c|}{ Objetivo } & Suporte Teórico \\
\hline $\mathbf{1}$ & Estatísticas descritivas & Descrever o conjunto de dados & Fávero (2009) \\
\hline $\mathbf{2}$ & Teste de normalidade & Verificar a distribuição dos dados & Fávero (2009) \\
\hline $\mathbf{3}$ & Correlações & Para medir a existência de auto correlações & $\begin{array}{c}\text { Gujarati (2006); } \\
\text { nos resíduos }\end{array}$ \\
\hline $\mathbf{4}$ & Breusch Pagan & Verificar a ausência de heterocedasticidade & Belfiore e Fávero (2017) \\
\hline $\mathbf{5}$ & Teste de Chow & Verificar se há quebra estrutural na regressão & Valle e Rebelo (2002) \\
\hline $\mathbf{6}$ & Teste dos retornos & Verificar os retornos normais e anormais & $\begin{array}{c}\text { Campbell, Lo e Mackinlay } \\
\text { (1997); Matsumoto, Baraldi e } \\
\text { Jucá (2018) }\end{array}$ \\
\hline
\end{tabular}

Fonte: elaborado pelos autores (2018).

De acordo com Fávero (2009), os testes paramétricos devem atender à normalidade, contudo, Brooks (2008) e Pino (2014) destacam que esse pressuposto pode ser quebrado desde que o teste aplicado seja robusto. Por se tratar de um estudo de eventos, com uma amostra de 37 ativos, o estudo de eventos comporta-se como um teste robusto, desde que os demais pressupostos sejam atendidos. Somente dois ativos atenderam a normalidade.

Seguindo para o teste da heterocedasticidade e autocorrelação o objetivo foi observar a robustez dos dados (GUJARATI, 2006; BELFIORE; FÁVERO, 2017). Para tanto, alguns ativos não atenderam ao pressuposto, uma das formas de verificar se os dados se apresentam robustos é avaliar a partir do erro padrão robusto. Assim sendo, optou-se por operacionalizar os testes novamente a partir da correção. 
Comportamento das ações das empresas listadas na B3 a partir da publicação do Ranking Merco Brasil

Por fim, foi realizado o teste de quebra estrutural por meio do teste de Chow. De acordo com Valle e Rebelo (2002, p. 7), "Chow reconhece também a importância de existir um teste estatístico que possibilite a comparação de apenas parte dos coeficientes dos dois modelos de regressão". Para o teste mencionado os ativos que demonstraram quebra estrutural foram removidos da amostra.

Com intuito de manter a qualidade da amostra, após a utilização do erro padrão robusto, alguns ativos foram retirados da amostra, a saber: ALPA4, BBAS3, BRKM3, CPFE3, GEOO34, HGTX3, JNJB34, MGLU3, VALE3, WEGE3, EMBR3 e LREN3. Os resultados dos testes mencionados estão descritos e discutidos na próxima seção.

\section{DESCRIÇÃO E ANÁLISE DOS DADOS}

A Tabela 2 contém as estatísticas descritivas dos ativos na janela de estimação e na janela do evento, os quais foram mantidos na amostra após os testes dos pressupostos.

Tabela 2 - Estatísticas Descritivas

\begin{tabular}{cccccccccc}
\hline & \multicolumn{3}{c}{ Janela de Estimação } & \multicolumn{2}{c}{ Janela de Eventos } & \multicolumn{3}{c}{ Janela de Estimação } & \multicolumn{2}{c}{ Janela de Eventos } \\
\hline \multicolumn{1}{c}{ Ativo } & Média & D. P. & Média & D. P. & Ativo & Média & D. P. & Média & D. P. \\
\hline ABEV3 (1) & $0,12 \%$ & $1,07 \%$ & $-0,24 \%$ & $0,96 \%$ & RADL3 (13) & $0,03 \%$ & $1,51 \%$ & $-0,08 \%$ & $1,35 \%$ \\
ALPA3 (2) & $0,22 \%$ & $2,61 \%$ & $0,00 \%$ & $3,62 \%$ & RENT3 (14) & $0,32 \%$ & $1,82 \%$ & $0,03 \%$ & $1,51 \%$ \\
BBDC3 (3) & $0,08 \%$ & $1,82 \%$ & $-0,02 \%$ & $2,13 \%$ & TOTS3 (15) & $0,05 \%$ & $1,66 \%$ & $0,68 \%$ & $1,62 \%$ \\
BBDC4 (4) & $0,10 \%$ & $1,72 \%$ & $0,04 \%$ & $1,86 \%$ & VIVIT4 (16) & $0,05 \%$ & $1,16 \%$ & $-0,13 \%$ & $1,35 \%$ \\
BRKM5 (5) & $0,13 \%$ & $1,93 \%$ & $-0,58 \%$ & $1,41 \%$ & AVON34(17) & $-0,21 \%$ & $3,22 \%$ & $-0,11 \%$ & $1,86 \%$ \\
FLRY3 (6) & $0,10 \%$ & $1,87 \%$ & $0,13 \%$ & $1,77 \%$ & ELET6 (18) & $-0,02 \%$ & $3,60 \%$ & $-0,42 \%$ & $2,50 \%$ \\
GFSA3 (7) & $-0,20 \%$ & $3,34 \%$ & $0,07 \%$ & $4,85 \%$ & GGBR3 (19) & $0,14 \%$ & $2,61 \%$ & $0,36 \%$ & $1,80 \%$ \\
GGBR4 (8) & $0,07 \%$ & $2,61 \%$ & $0,35 \%$ & $1,67 \%$ & GOAU3 (20) & $0,10 \%$ & $2,51 \%$ & $0,72 \%$ & $2,02 \%$ \\
GOAU4(9) & $0,09 \%$ & $3,03 \%$ & $0,57 \%$ & $2,07 \%$ & ITSA4 (21) & $0,14 \%$ & $1,55 \%$ & $-0,03 \%$ & $1,46 \%$ \\
GOLL4(10) & $0,40 \%$ & $3,54 \%$ & $-1,45 \%$ & $4,34 \%$ & NATU3 (22) & $0,06 \%$ & $2,23 \%$ & $0,29 \%$ & $2,18 \%$ \\
ITUB4 (11) & $0,10 \%$ & $1,61 \%$ & $0,01 \%$ & $1,38 \%$ & PETR4 (23) & $0,11 \%$ & $2,33 \%$ & $0,14 \%$ & $2,16 \%$ \\
PSSA3 (12) & $0,20 \%$ & $1,65 \%$ & $-0,21 \%$ & $1,51 \%$ & & & & & \\
\hline
\end{tabular}

Fonte: dados da pesquisa (2018).

As médias dos retornos dos ativos na janela de estimação demonstram valores próximos. Na janela do evento o ativo $\operatorname{GOLL} 4(-1,45)$ apresentou valor maior para a média. Os maiores valores para o desvio padrão na janela de estimação são GFSA (3,34\%), GOAU4 (3,03\%), GOLL4 (3,54\%), (3,14\%), AVON34 (3,22\%) e ELET6 (3,50\%), na janela do evento os ativos com maiores valores do desvio padrão foram ALPA3 (3,62\%), GFSA (4,85\%) e GOLL4 $(4,34 \%)$. Os resultados descritivos indicam que os ativos mencionados possuem maior volatilidade no mercado e indicam a sensibilidade dos retornos em relação as ocorrências no mercado acionário.

\subsection{RETORNOS ANORMAIS DAS EMPRESAS RANQUEADAS}

Com relação ao cálculo dos retornos diários, os mesmos foram realizados a partir dos retornos dos 23 ativos que integraram a amostra. A Tabela 3 demonstra os retornos anormais calculados para os ativos da amostra.

Tabela 3 - Cálculos dos Retornos dos Ativos

\begin{tabular}{|c|c|c|c|c|c|c|c|c|c|c|c|}
\hline & \multicolumn{11}{|c|}{ JANELA DO EVENTO } \\
\hline & $5 A$ & $4 A$ & 3a & 2a & 1 a & 0 & $1 \mathrm{~A}$ & $2 \underline{a}$ & $3 A$ & $4 A$ & $5 A$ \\
\hline 1 & $0,53 \%$ & $-0,23 \%$ & $-0,03 \%$ & $-0,61 \%$ & $-0,45 \%$ & $-0,21 \%$ & $-0,68 \%$ & $0,74 \%$ & $-2,09 \% * *$ & $0,31 \%$ & $-0,43 \%$ \\
\hline 2 & $-0,08 \%$ & $-0,06 \%$ & $-0,21 \%$ & $8,66 \%$ & $-3,46 \%$ & $-0,80 \%$ & $-0,21 \%$ & $-0,04 \%$ & $-7,16 \% *$ & $-1,13 \%$ & $1,05 \%$ \\
\hline 3 & $0,54 \%$ & $-0,75 \%$ & $0,19 \%$ & $-0,50 \%$ & $2,18 \% * *$ & $-1,78 \% * * *$ & $0,18 \%$ & $-1,45 \%$ & $0,75 \%$ & $0,74 \%$ & $-0,07 \%$ \\
\hline 4 & $-0,24 \%$ & $-1,02 \%$ & $-0,11 \%$ & $0,37 \%$ & $1,84 \% * *$ & $-1,96 \% * *$ & $1,00 \%$ & $-1,07 \%$ & $-0,30 \%$ & $-0,19 \%$ & $0,35 \%$ \\
\hline
\end{tabular}


Bruno Eduardo Slongo Garcia, Claudio Marcelo Edwards Barros e Marcos Wagner da Fonseca

\begin{tabular}{|c|c|c|c|c|c|c|c|c|c|c|c|}
\hline & \multicolumn{11}{|c|}{ JANELA DO EVENTO } \\
\hline & $5 A$ & $4 A$ & $3 \underline{a}$ & $2 \underline{a}$ & 19 & 0 & $1 \mathrm{~A}$ & $2 \underline{a}$ & 3A & $4 A$ & $5 A$ \\
\hline 5 & $-0,10 \%$ & $-1,92 \%$ & $0,39 \%$ & $-0,71 \%$ & $-3,63 \% * *$ & $-0,51 \%$ & $1,05 \%$ & $-0,60 \%$ & $0,82 \%$ & $-1,83 \%$ & $2,75 \%$ \\
\hline 6 & $2,29 \%$ & $0,15 \%$ & $-2,31 \%$ & $-0,91 \%$ & $0,96 \%$ & $1,11 \%$ & $-2,44 \%$ & $-1,56 \%$ & $-0,34 \%$ & $-0,03 \%$ & $3,92 \% * *$ \\
\hline 7 & $0,67 \%$ & $2,87 \%$ & $9,54 \% *$ & $-4,94 \%$ & $1,31 \%$ & $-0,30 \%$ & $0,29 \%$ & $-1,23 \%$ & $2,01 \%$ & $1,62 \%$ & $-0,31 \%$ \\
\hline 8 & $-1,02 \%$ & $-0,78 \%$ & $-1,35 \%$ & $0,45 \%$ & $0,83 \%$ & $-0,73 \%$ & $-2,07 \%$ & $0,42 \%$ & $0,21 \%$ & $3,74 \% * * *$ & $2,44 \%$ \\
\hline 9 & $-0,91 \%$ & $0,35 \%$ & $-1,18 \%$ & $-0,06 \%$ & $0,15 \%$ & $-0,63 \%$ & $-1,32 \%$ & $-1,07 \%$ & $2,05 \%$ & $1,98 \%$ & $1,95 \%$ \\
\hline 10 & $-7,33 \% * *$ & $-2,91 \%$ & $1,99 \%$ & $-2,62 \%$ & $-6,27 \% * *$ & $-2,14 \%$ & $0,75 \%$ & $-0,06 \%$ & $-3,21 \%$ & $-2,63 \%$ & $4,60 \%$ \\
\hline 11 & $-1,01 \%$ & $0,15 \%$ & $0,10 \%$ & $-0,32 \%$ & $-0,02 \%$ & $0,45 \%$ & $-0,29 \%$ & $-0,51 \%$ & $-2,44 \% *$ & $-0,24 \%$ & $-0,95 \%$ \\
\hline 12 & $0,01 \%$ & $-0,02 \%$ & $0,16 \%$ & $-2,45 \%$ & $1,54 \%$ & $-0,97 \%$ & $0,14 \%$ & $0,52 \%$ & $5,90 \%$ & $-1,76 \%$ & $-3,38 \% * *$ \\
\hline 13 & $-0,18 \%$ & $-1,30 \%$ & $-1,08 \%$ & $0,98 \%$ & $0,75 \%$ & $1,46 \%$ & $-0,76 \%$ & $-0,82 \%$ & $-3,12 \% * *$ & $-0,12 \%$ & $-3,59 \% *$ \\
\hline 14 & $-0,20 \%$ & $-1,50 \%$ & $-1,26 \%$ & $-1,00 \%$ & $3,38 \% * *$ & $-2,11 \%$ & $-5,21 \% *$ & $-0,71 \%$ & $-2,16 \%$ & $-0,59 \%$ & $-0,29 \%$ \\
\hline 15 & $1,34 \%$ & $-0,09 \%$ & $-0,05 \%$ & $0,02 \%$ & $-0,64 \%$ & $0,49 \%$ & $0,07 \%$ & $-0,10 \%$ & $-2,18 \%$ & $0,38 \%$ & $0,06 \%$ \\
\hline 16 & $-0,17 \%$ & $-0,66 \%$ & $0,05 \%$ & $0,72 \%$ & $-0,25 \%$ & $0,02 \%$ & $0,50 \%$ & $-0,92 \%$ & $1,11 \%$ & $-1,28 \%$ & $-1,01 \%$ \\
\hline 17 & $0,22 \%$ & $3,68 \%$ & $0,21 \%$ & $0,27 \%$ & $0,35 \%$ & $-0,14 \%$ & $0,21 \%$ & $0,32 \%$ & $0,66 \%$ & $0,58 \%$ & $0,28 \%$ \\
\hline 18 & $1,00 \%$ & $-3,69 \%$ & $-0,41 \%$ & $0,34 \%$ & $4,10 \%$ & $-1,99 \%$ & $5,50 \% * * *$ & $-1,56 \%$ & $5,15 \% * * *$ & $-1,03 \%$ & $3,35 \%$ \\
\hline 19 & $-1,35 \%$ & $1,56 \%$ & $-1,63 \%$ & $-1,12 \%$ & $0,60 \%$ & $0,73 \%$ & $-2,83 \%$ & $-0,59 \%$ & $-0,60 \%$ & $3,20 \%$ & $2,11 \%$ \\
\hline 20 & $-0,95 \%$ & $0,42 \%$ & $-0,81 \%$ & $1,24 \%$ & $-0,99 \%$ & $-0,08 \%$ & $-1,86 \%$ & $0,05 \%$ & $1,77 \%$ & $0,26 \%$ & $2,24 \%$ \\
\hline 21 & $-1,69 \% * *$ & $-0,53 \%$ & $0,26 \%$ & $-0,11 \%$ & $1,10 \%$ & $1,42 \% * * *$ & $0,01 \%$ & $-0,22 \%$ & $-4,16 \% *$ & $-1,17 \%$ & $-1,45 \% * * *$ \\
\hline 22 & $0,55 \%$ & $2,85 \%$ & $-2,70 \%$ & $0,89 \%$ & $0,71 \%$ & $-1,68 \%$ & $2,59 \%$ & $-3,07 \% * * *$ & $4,54 \% * *$ & $-1,28 \%$ & $-0,02 \%$ \\
\hline 23 & $1,75 \%$ & $1,23 \%$ & $0,46 \%$ & $-0,10 \%$ & $-2,24 \%$ & $1,64 \%$ & $0,26 \%$ & $1,75 \%$ & $1,25 \%$ & $1,68 \%$ & $-0,47 \%$ \\
\hline
\end{tabular}

Nota: * indica significância de $1 \%, * *$ indica a significância de $5 \%, * * *$ indica a significância de $10 \%$.

Fonte: dados da pesquisa (2018).

Os resultados demonstram retornos anormais pulverizados, distribuídos na janela do evento. Ao nível de significância de $10 \%$ são identificados os ativos das companhias Bradesco, Gerdau, Eletrobrás, Itaú e Natura. A significância de 5\% a Ambev, Bradesco, Braskem, Fleury, Gol, Porto Seguro, Raia Drogasil, Localiza, Itaú e Natura e ao nível de significância de $1 \%$ Alpargatas, Gafisa, Itaú, Raia Drogasil e Localiza apresentaram retornos anormais.

Ocorreram retornos anormais em 16 (70\%) dos 23 ativos analisados na janela do evento, sendo 10 ocorrências distribuídas em: um dia antes do evento, na data do evento ou um dia após a ocorrência da divulgação do ranking. As ocorrências de retornos anormais sob a lente da Teoria da Sinalização pressupõem que a incerteza dos retornos é suprimida pela emissão dos sinais no mercado. As informações indicam aos investidores como os ativos irão se comportar, reduzindo as assimetrias informacionais.

Neste sentido, para afirmar que existem retornos anormais nos ativos listados a partir da divulgação do Ranking Merco, os retornos deverão propiciar oscilações generalizadas no conjunto de ações, esta afirmação não foi identificada na amostra estudada. Os reflexos em parte dos ativos (70\%) são acompanhados por pulverizações na janela do evento, o que não permite afirmar que o ranking isoladamente provoca retornos anormais diferentes de zero em toda a amostra.

O referencial a respeito da reputação corporativa apresentado neste estudo pode explicar os retornos em parte da amostra. Os autores desta pesquisa concordam que a reputação corporativa é um resultado de um processo cognitivo de identificação (ARGENTI; FORMAN, 2002; DUTRA; PARENTE, 2018). Partindo desse entendimento, é notório reconhecer que esta variável pode ter se apresentado na cultura organizacional das companhias listadas no Merco e devido a isso não se comportam como sinalizadora.

Para melhor compreender este argumento, considerando as particularidades das companhias, recorre-se a análises dos eventos secundários e o histórico do Ranking Merco. Para tanto, o contexto é a ocorrência de retornos anormais em três ativos no dia do evento, o qual foi divulgado no dia 18 de abril de 2018 na revista Exame. A notícia veiculada em seu portal online teve como título "Uma pesquisa exclusiva lista as companhias com melhor 
reputação no Brasil e mostra quais delas já conseguiram reverter o período de baixa e melhorar a própria imagem com o reaquecimento da economia".

A partir da divulgação do ranking é possível considerar que cada companhia e seu respectivo setor possuem características específicas, mas o conteúdo informacional da divulgação suscitou um evento em âmbito nacional: a recuperação econômica, posteriormente mencionando a reputação. $O$ setor de alimentos, bebidas e fumo, cosméticos e perfumes, energia, indústria da construção, varejo, mineração, siderurgia e metalurgia, química e petroquímica, roupas e calçados, seguros, saúde, diversos, financeiros e transporte e logística apresentaram retornos anormais em alguns dos ativos listados.

A análise por setor demonstrou que não foram todos os ativos listados que tiveram retornos anormais. O comportamento no setor de cosméticos e perfumes, por exemplo, composto pela Avon e Natura, destacou efeitos sobre os ativos da Natura, mas a Avon não teve retornos anormais significativos. Reforçando a sinalização da divulgação do ranking, sites do setor de cosméticos mencionaram a Natura e Avon como as representantes da reputação corporativa. As matérias divulgadas enaltecem a colocação das empresas sob o título "mercado de vendas diretas no Brasil aposta em expansão". No decorrer da matéria, foi destacada a reputação das companhias Natura e Avon, as empresas foram denominadas como 'gigantes do setor' que recuperaram o nível de vendas a partir da reputação, mas os retornos dos ativos se mantiveram normais.

As ações de divulgação a respeito da colocação no ranking de reputação são esforços que sinalizam no mercado em que as companhias se encontram e, por consequência, podem contribuir como um evento secundário de baixo impacto. Ao observar os demais setores é possível constatar que não produziram conteúdo informacional sobre a divulgação do ranking, mas tiveram retornos anormais em alguns dos ativos listados.

As informações sinalizadoras atuam em mercados com características de assimétricas (Dalmácio, 2009), o que foi identificado apenas em alguns setores das companhias listadas no Merco. Para explicar esse comportamento distinto, os autores (2009) recorrem ao entendimento de reputação corporativa como um processo de identificação. Trata-se de um processo cognitivo do mercado para com a empresa (ARGENTI; FORMAN, 2002; DUTRA; PARENTE, 2018).

Prosseguindo a afirmação de Dalmácio (2009), em que os setores agem distintamente a sinalização e podem ser afetados por outros fatores, a composição do ranking em edições anteriores podem caracterizar sinalizações secundárias. Para tanto, observou-se que as empresas listadas no ranking de 2017, em sua maioria, já estiveram presentes em outras edições de rankings de reputação corporativa, conforme destacado na Tabela 4. 
Tabela 4 - Classificações das Companhias em Edições Anteriores

\begin{tabular}{|c|c|c|c|c|}
\hline \multirow[b]{2}{*}{ COMPANHIAS } & \multicolumn{4}{|c|}{ Ano do ranking } \\
\hline & 2017 & 2016 & 2014 & 2013 \\
\hline NATURA & 1 & 1 & 1 & 1 \\
\hline ALPARGATAS & 52 & 31 & 49 & 43 \\
\hline AMBEV & 5 & 3 & 3 & 7 \\
\hline AVON & 25 & $* *$ & $* *$ & $* *$ \\
\hline BRASKEM & 82 & $* *$ & $* *$ & $* *$ \\
\hline BRADESCO & 31 & 16 & 8 & 10 \\
\hline ELETROBRAS & 81 & $* *$ & 66 & 88 \\
\hline GAFISA & 93 & 98 & $* *$ & $* *$ \\
\hline GERDAU & 16 & 20 & 9 & 6 \\
\hline GOL & 69 & 71 & $* *$ & $* *$ \\
\hline GRUPO FLEURY & 74 & 34 & 53 & 37 \\
\hline ITAÚ UNIBANCO & 3 & 2 & 2 & 4 \\
\hline LOCALIZA & 58 & 72 & 85 & 55 \\
\hline LOJAS RENNER & 41 & 32 & 43 & 52 \\
\hline MAGAZINE LUIZA & 28 & 38 & 32 & 26 \\
\hline PETROBRAS & 91 & 92 & 7 & 3 \\
\hline PORTO SEGURO & 26 & 42 & 37 & 97 \\
\hline RAIA DROGASIL & 57 & 63 & $* *$ & $* *$ \\
\hline TELEFÔNICA BRASIL & 84 & 85 & 76 & 79 \\
\hline TOTVS & 75 & 64 & 76 & 76 \\
\hline VALE & 68 & 70 & 6 & 2 \\
\hline WEG & 63 & 84 & 67 & 57 \\
\hline
\end{tabular}

Nota: ${ }^{* *}$ a companhia não esteve ranqueada no respectivo ano.

Fonte: elaborado pelos autores (2018).

Companhias como a Eletrobrás e a Braskem não estavam relacionadas no ranking de 2016 e apresentaram retornos anormais próximos ao evento. Não foram encontrados eventos secundários emitidos pelas companhias, demonstrando que os ativos agem com comportamentos semelhantes, quando o conteúdo informacional é relevante e compreendido como uma novidade para o mercado (DALMÁCIO, 2009; JANISZEWSKI et al., 2017). A participação das companhias em edições anteriores torna a informação da composição do ranking defasada, uma vez que os efeitos da sinalização sobre as ações tornam-se pulverizados.

Essa afirmação apresenta-se de forma diferente nos ativos do Bradesco, o qual esteve em outras edições do mesmo ranking, ficando cerca de 20 posições abaixo na edição de 2017. Ainda assim, após a mudança de posição, as ações do Bradesco apresentaram retornos anormais próximos ao evento. Para tanto, a sinalização irá ocorrer quando a informação proporcionar os processos cognitivos de identificação com o mercado.

A afirmação encontra respaldo quando analisados estudos como o proposto por Melo e Fonseca (2015), em que a divulgação de informações consideradas relevantes no mercado acionário causa retornos anormais. Neste sentido, o conceito de relevante assume que a informação é nova ou acresce o valor a companhia. Ao tratar informações consideradas relevantes para sinalizar algo ao mercado, Lima e Terra (2004) mencionam que as informações contidas na demonstração do resultado do exercício (DRE) possuem capacidade de influenciar os retornos no mercado brasileiro, destacando, inclusive, que se trata de um mercado semiforte em que as informações são selecionadas.

Castro e Marques (2013) contrapõem a ideia de sinalização na divulgação da informação, os autores atribuem os retornos anormais aos papéis assumidos com a divulgação de determinadas informações. Os achados (CASTRO; MARQUES, 2013) se assemelham aos 
apresentados neste estudo, em que os retornos anormais pulverizados e específicos são explicados quando o mercado considera uma informação "nova" e, assim sendo, iniciam o processo de identificação para com a companhia.

A afirmação é fortalecida no estudo de Batista, Oliveira e Macedo (2016), ao contemplarem que a relevância da informação reflete no desempenho da empresa. Se o ranking já havia acometido a inclusão da empresa em edições anteriores é reforçada a perspectiva de uma cultura organizacional de reputação corporativa, o que invalida os retornos anormais em grande parte das companhias estudadas, deixando-os pulverizados.

Outra questão que fortalece a perspectiva da informação relevante é observada nos retornos anormais positivos para companhias que caíram posições no ranking, como observado nos ativos do Bradesco e Ambev. Mesmo com o declínio nas posições o Bradesco e a Ambev demonstram retornos anormais, o que pode significar que o mercado valoriza a presença das empresas no Merco.

Companhias como a Natura, mantem a mesma posição em quatro edições do Merco, bem como o Itaú Unibanco que se mantem nas primeiras colocações nas mesmas edições. Isso demonstra que a informação afeta ativos específicos. Devido as características do mercado a capacidade de cognição e identificação do mesmo para com a companhia pode alterar a identificação entre empresas e público-alvo.

Por fim, é relevante destacar que a não observância de retornos anormais não caracteriza a reputação corporativa como irrelevante, mas, sobretudo, demonstra que as informações sobre o desempenho, tendem a perder a característica de sinalização em mercados específicos, à medida que são conhecidas e incorporadas nesses mercados.

\section{DISCUSSÃO DOS RESULTADOS}

Este estudo partiu da constatação da lacuna descrita por Money (2017) a respeito da relação circular entre ações estratégicas (colocação em um ranking), observação do público interessado e resultados esperados. Para tanto, a reputação corporativa é abordada como a admiração e respeito que os indivíduos possuem em relação a uma organização em determinado momento (DOWLING, 2016).

Os achados deste estudo demonstram que o conceito de reputação descrito por Dowling (2016) pode ser interpretado em dois momentos, a saber: (i) quando as ações para a reputação são uma novidade ou consideradas relevantes e, (ii) quando já estão integradas à cultura organizacional ou perdem sua relevância. Quando a informação é novidade ou relevante os mercados semifortes, como é o caso do Brasil, podem reagir com retornos anormais, pois as informações podem reduzir as assimetrias no mercado de ações. Entretanto, quando a reputação está na cultura organizacional ou a informação não é relevante, o mercado tende a não reagir com a informação emitida.

Neste sentido, é possível observar que os retornos dos ativos analisados são pulverizados em parte da amostra ( $70 \%$ dos ativos) e não significativos em outra parte (30\% dos ativos). Desta forma, a edição do Ranking Merco de 2017 é uma sinalização de baixo impacto, isso devido a característica da informação, que pode não representar uma novidade para o mercado. Cerca de $70 \%$ dos ativos possuem retornos anormais, mas são distribuídos na janela do evento. A pulverização pode ser explicada por meio das ações estratégicas mencionadas por Money (2017), em que as companhias listadas podem divulgar suas ações de reputação corporativa antes da publicação do ranking. Assim, tem-se um esforço contínuo em demonstrar ao mercado quais ações estão sendo tomadas e quais os impactos para a 
empresa, ativando os processos cognitivos de identificação antes da publicação do Merco. Desta forma, o ranking não será uma informação considerada nova e, portanto, perde sua relevância para sinalizar e promover retornos anormais.

A relevância da informação para o mercado é discutida em diversos estudos (CASTRO; MARQUES, 2013; BATISTA; OLIVEIRA; MACEDO, 2016), o presente estudo concorda com os achados dos estudos mencionados. Desta forma, para que ocorram retornos anormais é necessário que a informação seja uma novidade ao mercado, atuando como sinalizadora da reputação da companhia. Podendo ativar os processos cognitivos de identificação que fazem com que os agentes mudem seu comportamento em relação aos ativos, promovendo retornos anormais.

Outro ponto que pode justificar a pulverização, encontra-se relacionado à cultura organizacional. A cultura e sua relação com reputação é inexplorada em estudos seminais, como de Hatch e Schultz (1997), contudo, ao afirmarem que a reputação corporativa é constituída por símbolos fornecem um caminho para associar cultura e reputação. Os símbolos como as ações cotidianas da companhia, o discurso institucional e a colocação recorrente em rankings são elementos que integram a cultura das organizações e, consequentemente, influenciam a reputação. Conforme o mercado percebe a divulgação no ranking como algo recorrente para a companhia, pode compreender que a reputação constitui a cultura dessa organização. Sendo assim, não proporciona ou minimiza os processos cognitivos de identificação da reputação corporativa, reduzindo ou extinguindo a capacidade de gerar retornos anormais.

Quando há um esquema positivo já constituído, a tendência é que essa informação não seja uma sinalização, diferentemente do ocorrido quando o esquema de interpretação da empresa for negativo. Diante do exposto, os autores deste estudo concordam com o conceito de Dowling (2016), ao afirmar que a reputação é um processo de admiração e respeito, inclusive, em um determinado período de tempo. Acrescenta-se que a reputação constituída na cognição necessita de reforços por meio de informações e ações estratégicas relevantes, para então, tornar-se uma sinalização, influenciando o comportamento dos agentes e dos ativos das empresas. Cada mercado agirá de acordo com as suas características, isto incluí a maneira com que o processo cognitivo de identificação é ativado nos indivíduos. Para tanto, reconhecer a relevância da informação, das ações estratégicas e sinalizações secundárias se faz necessário para que a reputação corporativa seja uma sinalização ao mercado.

\section{CONSIDERAÇÕES FINAIS}

O presente estudo buscou responder a seguinte problemática: "qual o comportamento das ações das empresas brasileiras listadas na B3 a partir da publicação do ranking de reputação corporativa Merco?" Para responder à questão proposta, os autores utilizaram a ótica da Teoria da Sinalização e os retornos dos ativos das companhias listadas no Ranking Merco 2017. Como resposta ao problema proposto, afirma-se que os ativos, bem como o mercado das companhias listadas, agem de forma distinta. Nos mercados perfeitos as informações não irão modificar os retornos dos ativos. Comportamento diferente ao observado em mercados imperfeitos, em que a informação pode caracterizar uma sinalização que corrige as assimetrias mercadológicas e antecipa o comportamento das ações.

Os resultados do presente estudo levaram a identificação de retornos anormais em $70 \%$ das observações da amostra, com base no conteúdo informacional da divulgação do Ranking Merco. Contudo, embora ocorram retornos anormais, o que pode demonstrar que a informação provocou efeitos no mercado, os retornos são pulverizados em relação ao dia do 
evento e não podem ser considerados como resultado da sinalização. Uma possível explicação para o comportamento constatado está no conceito de reputação corporativa como uma construção de identidade por meio da cognição, uma relação entre companhia e mercado.

Neste sentido, a escolha dos autores deste estudo em utilizar a Teoria da Sinalização demonstrou ser uma lente teórica adequada para analisar os achados. Determinadas informações, embora divulgadas em escala internacional, como o Ranking Merco, não apresentam conteúdo informacional capaz de ser assimilado pelo mercado e, portanto, são insuficientes para provocar retornos anormais nos ativos negociados. $O$ fato de parte das ações aqui estudadas (30\%) demonstrarem retornos normais na janela do evento, pode ser explicada pela inclusão das companhias em edições anteriores do Merco e, este fato não constitui mais uma sinalização.

O comportamento das ações das empresas ranqueadas apresentou diferenças na amostra em virtude do conteúdo informacional do ranking e do processo de identificação do mercado e a empresa. Ao analisar os rankings anteriores foi possível identificar que algumas empresas integrantes da amostra foram listadas em outras edições, fato este que reduz a sinalização da informação e pulveriza os retornos. As companhias listadas em anos anteriores integram a reputação corporativa como parte de sua cultura organizacional, e como tal, tornase um comportamento esperado. Como consequência, o histórico da reputação das companhias suprime os efeitos sobre o preço das ações, conforme observado na diminuição das assimetrias do mercado dos ativos estudados.

Portanto, para ser atribuída como um sinal, a informação precisa ser reconhecida pelo mercado. No caso do mercado brasileiro, que apresenta características de semiforte, a capacidade de produzir assimetrias fica limitada ao conteúdo informacional e os processos cognitivos de identificação.

Embora a discussão apresentada neste estudo seja objeto de outras pesquisas, como o proposto por Cardoso et al. (2013) e De Luca et al. (2015), que afirmam a ocorrência de influência entre reputação e desempenho, foi observado que a divulgação do Ranking Merco não produziu conteúdo informacional na edição de 2017 que ocasione dinâmica nos retornos de todos os ativos analisados. Desta forma, a sinalização e os efeitos sobre as ações em cerca de $30 \%$ da amostra foram absorvidos em edições anteriores do mesmo ranking, possivelmente por meio de processos cognitivos de identificação do mercado.

Considerando os resultados relatados, o presente estudo contribui para compreensão da relevância da informação como uma novidade no mercado de ações, que pode incitar oscilações nos retornos dos ativos. Outra contribuição está na discussão sobre a necessidade do processo de identificação entre companhia e mercado, que pode exercer efeito sobre o mercado e, posteriormente, sobre os retornos. Ademais, este estudo levantou questões a respeito da incorporação do conteúdo informacional como constituinte da cultura das companhias listadas. Por fim, buscou-se ampliar as discussões a respeito da reputação corporativa e os efeitos sobre o mercado de ações, considerando e respeitando as peculiaridades de cada setor. Foi demonstrado que os ativos agem de forma diferente diante da divulgação da mesma informação.

Como estudos futuros, sugere-se identificar se em algum dos anos anteriores o ranking foi capaz de produzir retornos anormais em todas as companhias listadas, corroborando com a afirmação sobre a relevância da informação. Outra sugestão é analisar as estratégias de sinalização que produzem efeitos no mercado de ações brasileiro em relação ao observado em mercados de outros países. 


\section{REFERÊNCIAS}

AGEEVA, E. MELEWAR, T.C.; FOROUDI, P.; DENNIS, C.; JIN, Z. Examining the influence of corporate website favorability on corporate image and corporate reputation: Findings from fsQCA. Journal of Business Research, v. 89, p. 287-304, 2018. DOI: https://doi.org/10.1016/j.jbusres.2018.01.036.

AGUIAR, A. B.; CORRAR, L. J.; BATISTELLA, F. D. Adoção de práticas de governança corporativa e o comportamento das ações na Bovespa: evidências empíricas. Revista de Administração da Universidade de São Paulo, São Paulo, v. 39, n.4, p. 189-208, 2004.

BARNEY, J. Firm resources and sustained competitive advantage. Journal of management, v. 17, n.1, p. 99-120, 1991.

BARROS, C. M. E.; LOPES, I. F.; ALMEIDA, L. B. Efeito contágio da operação carne fraca sobre o valor das ações dos principais players do mercado de proteínas do Brasil e do México. Enfoque: Reflexão Contábil, Maringá, v. 38, n. 1, p. 105-122, 2019. DOI: https://doi.org/10.4025/enfoque.v38i1.39966.

BATISTA, T. C.; OLIVEIRA, J. F.; DA SILVA MACEDO, M. A. Relevância da informação contábil para o mercado brasileiro de capitais: uma análise comparativa entre lucro líquido, lucro abrangente e fluxo de caixa operacional. Revista de Administração, Contabilidade e Economia, Joaçaba, v. 16, n.1, p. 381-408, 2017. DOI: http://dx.doi.org/10.18593/race.v16i1.12052.

CALEGARI, I. P.; DESOUZA GONÇALVES, R.; SERRANO, A. L. M.; RODRIGUES, J. M. Efeitos da reputação corporativa no custo de capital próprio em empresas brasileiras listadas. Revista Universo Contábil, Blumenau, v. 12, n.1, p. 178 - 198, 2016.

DOI: http//:10.4270/ruc.2016110.

CAMARGOS, M. A. D.; VIDAL BARBOSA, F. Eficiência informacional do mercado de capitais brasileiro pós-Plano Real: um estudo de eventos dos anúncios de fusões e aquisições. Revista de Administração da Universidade de São Paulo, São Paulo, v. 41, n. 1, p. 43 -58, 2006. DOI: https://doi.org/10.1590/S0080-21072006000100004.

CAMPBELL, J. Y.; LO, A. W. C.; MACKINLAY, A. C. The econometrics of financial markets. New Jersey: Princeton, 1997.

CARDOSO, V. I. C.; DE LUCA, M. M. M.; LIMA, G. A. S. F; VASCONCELOS, A. C. Reputação corporativa nas empresas brasileiras: uma questão relevante para o desempenho empresarial? Revista Contemporânea de Contabilidade, Florianópolis, v. 10, n. 21, p. 115 136, 2013. DOI: http://dx.doi.org.br/10.5007/2175-8069.2013v10n21p115.

CARNAÚBA, W. M. Estrutura de capital: teoria da agência, teoria da sinalização e teoria do controle. 1993. Dissertação (Mestrado em Administração) - Escola de Administração de Empresas, Fundação Getúlio Vargas: São Paulo: 1993. 
Comportamento das ações das empresas listadas na B3 a partir da publicação do Ranking Merco Brasil

DALMÁCIO, F. Z. Mecanismos de governança e acurácia das previsões dos analistas do mercado brasileiro: uma análise sob a perspectiva da teoria da sinalização. 2009. Tese (Doutorado em Administração) - Faculdade de Economia, Administração e Contabilidade, Universidade de São Paulo: São Paulo, 2009.

DE LUCA, M. M. M.; GÓIS, A. D.; COSTA, J. A.; MAIA, A. J. R. Reputação Corporativa e a Criação de Riqueza nas Empresas Listadas na BM\&FBovespa. Revista de Ciências da Administração, Florianópolis, v. 1, n. 2, p. 51-63, 2015. DOI: https://doi.org/10.5007/21758077.2015v17n42p51.

DOWLING, G. R. Defining and measuring corporate reputations. European Management Review, v. 13, n. 3, p. 207-223, 2016. DOI: https://doi.org/10.1111/emre.12081.

DUTRA, R. S.; PARENTE, P. H. N.; DUTRA, G. B. M.; PARENTE, L. O. D. S. S. Governança corporativa e desempenho empresarial: uma análise sob o enfoque da reputação corporativa das empresas brasileiras. Revista de Auditoria Governança e Contabilidade, Monte Carmelo, v. 6, n. 26, p. 47-63, 2018.

FRANCO, C.; BACH, T. M.; SILVA, E. D. D. Assimetria de informação e desempenho: Um estudo em empresas de capital aberto no Brasil. Revista de Gestão dos Países de Língua Portuguesa, Rio de Janeiro, v. 15, n. 2, p. 24-39, 2016.

GÓIS, A. D.; DE LUCA, M. M. M.; DE LIMA, G. A. S. F.; DE VASCONCELOS, A. C. Reputação gera valor para os acionistas? uma análise nas empresas brasileiras. Revista de Administração, Contabilidade e Economia, Joaçaba, v. 16, n. 2, p. 523-546, 2017. DOI:

10.18593/race.v16i2.13048.

GÓIS, A. D.; DE LUCA, M. M. M.; SOUSA, N. M. Reputação Corporativa e Oportunidade de Crescimento. Revista Organizações em Contexto online, São Paulo, v. 13, n. 25, p. 299-322, 2017.

HATCH, M.; SCHULTZ, M. Relations between organizational culture, identity and image. European Journal of marketing. Bingley, v. 3, n. 5, p. 356-365, 1997.

DOI: https://doi.org/10.1108/eb060636.

JANISZEWSKI, V. J.; CARRASCOSO, L. A.; FÉLIX JÚNIOR, L. A.; LAGIOIA, U. C. T.; OLIVEIRA, M. F. J. Relação da Teoria da Sinalização com o Desempenho das Empresas a partir dos seus Indicadores de Performance de Divulgação Voluntária. Revista Contabilidade e Controladoria, Curitiba, v. 9, n. 2, p. 93-108, 2017.

DOI: http://dx.doi.org/10.5380/rcc.v9i2.52264.

KOPORCIC, N.; HALINEN, A. Interactive Network Branding: Creating corporate identity and reputation through interpersonal interaction. IMP Journal, v. 12, n. 2, p. 392-408, 2018. DOI: https://doi.org/10.1108/IMP-05-2017-0026. 
LOPES, A. C.; DE LUCA, M. M. M.; GÓIS, A. D.; DE VASCONCELOS, A. C. Disclosure Socioambiental, Reputação Corporativa e Criação de Valor nas Empresas Listadas na BM\&FBovespa. Revista Ambiente Contábil, Natal, v. 9, n. 1 , p. 364- 382, 2017.

MACKINLAY, A. C. Event studies in economics and finance. Journal of economic literature, $v$. 35, n. 1, p. 13-39, mar. 1997.

MELO, F. J.; DA FONSECA, M. W. Política de dividendos no Brasil: uma análise na reação do mercado a anúncios de distribuição de proventos. Revista Contemporânea de

Contabilidade, Florianópolis, v. 12, n. 27, p. 137-164, 2015.

DOI: https://doi.org/10.5007/2175-8069.2015v12n27p137.

MONEY, K. SARAEVA, A.; GARNELOGOMEZ, I.; PAIN, S.; HILlENBRAND, C. Corporate reputation past and future: A review and integration of existing literature and a framework for future research. Corporate Reputation Review, v. 20, n. 3-4, p. 193-211, 2017. DOI: https://doi.org/10.1057/s41299-017-0034-3.

MONITOR EMPRESARIAL DE REPUTAÇÃO CORPORATIVA . Ranking de reputação corporativa Merco 2017. Disponível em: https://www.merco.info/br/ranking-mercoempresas?edicion=2017. Acesso em: 15 jun. 2019.

NOVIS NETO, J. A. N.; SAITO, R. Pagamentos de dividendos e persistência de retornos anormais das ações: evidência do mercado brasileiro. Revista de Administração da Universidade de São Paulo, São Paulo, v. 38, n. 2, p. 135 - 143, 2003.

PITTA, C. E. Risco e retorno do investimento imobiliário: um estudo do mercado de imóveis comerciais de São Paulo. 2000. Dissertação (Mestrado em Administração) - Escola de Administração de Empresas, Fundação Getúlio Vargas: São Paulo, 2000.

RAVASI, D.; RINDOVA, V.; ETTER, M.; CORNELISSEN, J. The formation of organizational reputation. Academy of Management Annals, Nova York, v. 12, n. 2, p. 574-599, 2018. DOI: https://doi.org/10.5465/annals.2016.0124.

SCHMIDT, P.; MARTINS, M. A. D. S.; SANTOS, J. L. D. Impactos da zelotes nas ações das empresas envolvidas. Revista de Administração FACES Journal, Belo Horizonte, v. 17, n. 2, p. 114-113, 2018. DOI: http://dx.doi.org/10.21714/1984-6975FACES2018V17N2ART5378.

SCHOEMAKER, P. J. Strategy, complexity, and economic rent. Management science, Catonsville, v. 36, n. 10, p. 1178-1192, 1990. DOI: https://doi.org/10.1287/mnsc.36.10.1178.

THOMAZ, J. C.; BRITO, E. P. Z. Reputação corporativa: construtos formativos e implicações para a gestão. Revista de Administração Contemporânea, Maringá, v. 14, n. 2, p. 229 - 250, 2010. DOI: https://doi.org/10.1590/S1415-65552010000200004.

WALSH, G.SCHAARSCHMIDT, M.; IVENS, S.. Effects of customer-based corporate reputation on perceived risk and relational outcomes: empirical evidence from gender moderation in 
Comportamento das ações das empresas listadas na B3 a partir da publicação do Ranking Merco Brasil

fashion retailing. Journal of Product \& Brand Management, v. 26, n. 3, p. 227-238. 2017. DOI: https://doi.org/10.1108/JPBM-07-2016-1267. 